\title{
Patent Attorney Combines the Law with Materials Research
}

In 2004, 15 years after I first started studying metallurgy and materials science, I entered my first steel mill. I had been visiting Sweden to work with a client in the patent department at Sandvik $A B$, which is a large multinational industrial conglomerate headquartered in Sweden that, among other things, manufactures specialty steels and cutting tool inserts.

As a patent attorney, I refer to materials research every day in my job.* I collaborate weekly, if not daily, with researchers, product managers, and attorneys at companies with respect to the protection and enforcement of their intellectual property that are as varied as the research and products of the company. As a result, the technical variation on a project-by-project basis is large, requiring continuous efforts to understand the materials science of these inventions. In this article, I examine a few of the ways in which materials research plays a role in the daily work of a patent attorney.

\section{Preparing Patent Applications}

One of my primary responsibilities with respect to the representation of Sandvik AB is the preparation of patent applications. Although patent applications require a highly stylized form of writing, the text is similar to the composition of a scientific journal submission or a presentation accompanying a lecture course or laboratory demonstration, all of which share the common goal of teaching and enabling others to practice the described technology.

Typically, the researchers with whom I collaborate provide a disclosure of the invention, including a brief description of the invention and the problem it intends to solve or the improvement it intends to provide, and any relevant figures and/or

\footnotetext{
*The patent bar in the United States is composed of roughly 50,000 individuals who have qualified to represent patent applicants in proceedings in the U.S. Patent and Trademark Office (USPTO). Qualification is predicated on having an appropriate technical background and passing a test on procedures in the USPTO. Suitably qualified technical people can represent patent applicants in the USPTO as patent agents; a law degree is not required for this aspect of a career in patent law. For more information on being registered at the USPTO, see Web site at www.uspto.gov. Patent attorneys have both a USPTO registration and are admitted to the bar in at least one jurisdiction. Patent attorneys can, in addition to representing applicants before the USPTO, represent a party in federal court.
}

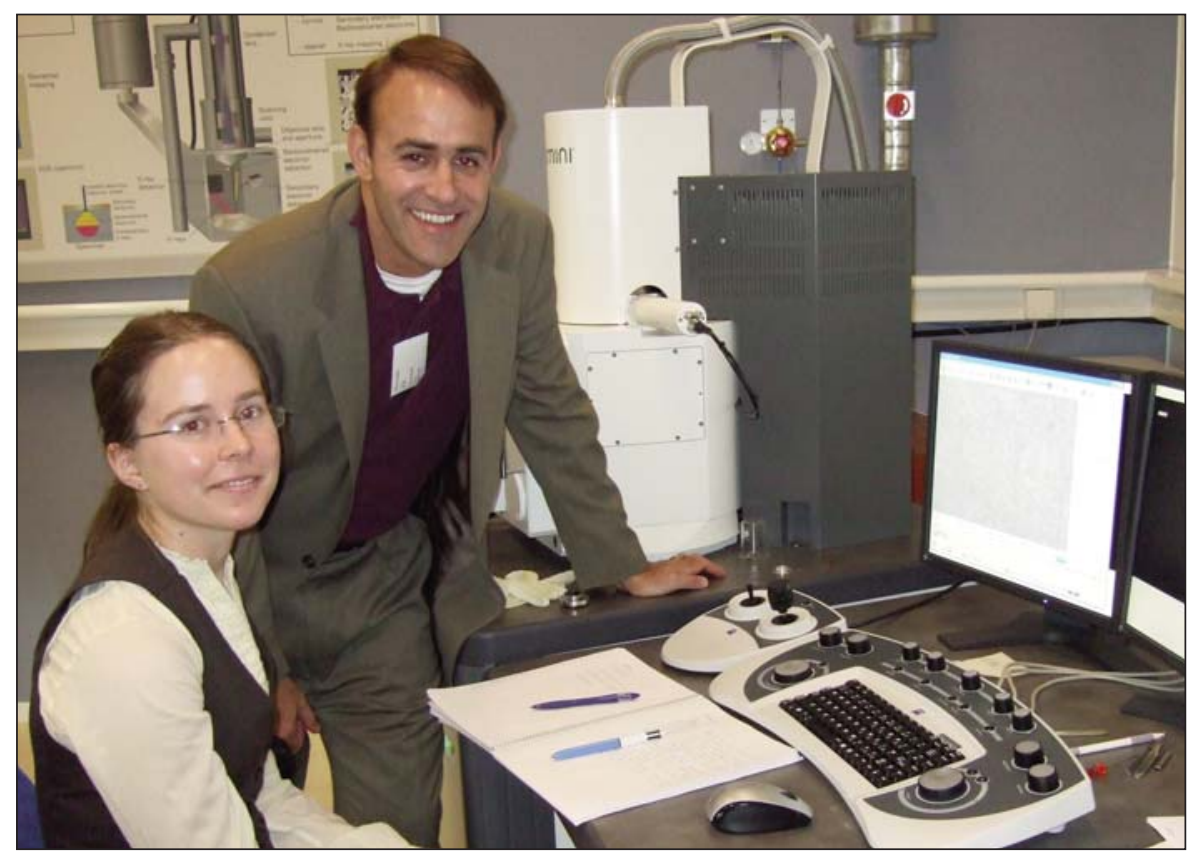

Patent attorney Jeffrey G. Killian (standing) reviews scanning electron microscope results with researcher Åsa Larsson during a recent visit to the research group of Sandvik AB.

test results. The details of the disclosure vary by the type of invention. For example, the information contained in the disclosure for a composition of a new alloy is different from that in the disclosure for a new processing method. Some applications with which I have been involved include composition of alloys such as copper-based alloys and duplex stainless steels with improved corrosion resistance or increased high temperature strength. A large percentage of applications for cutting tool applications relate to the composition and deposition of coatings, particularly multilayer coatings, with particular adhesion properties and crystallographic properties.

Reviews of these disclosures always take me back to my technical roots. In effect, I review a brief technical report produced by the researchers. If a composition of a new alloy is involved, the disclosure materials may include constituent element ranges, graphs of the relevant materials properties, and illustrations of the effects of various properties when the amount of each element is varied. If a resulting microstructure is important to the invention, scanning electron micrographs may be included to show the average grain size or distribution of precipitates. If a crystal structure is relevant to the invention, a texture coefficient may be disclosed.

My work also consists of preparing process patents, such as for a new heat treatment regime. Here, the disclosure materials may include details of the timeat-temperature curve, as well as results from comparative examples in which different parameters of the heat treatment are varied. In both cases, test results for the final product are typically included.

When I finish reviewing all of the disclosure materials, I discuss details of the invention with its inventors in order to clarify some aspects. I conduct these interviews in person whenever possible, which generally includes a visit to the laboratory and a demonstration of the invention. Since I spend most of my day at a desk, I particularly enjoy returning to the laboratory for such visits; with my materials background, these visits allow me to engage in a more intensive technical conversation with the inventor.

I also review background references in connection with the preparation of a patent application, an activity which will be familiar to anyone who has been in a graduate or research program. Finally, when all the details have been obtained and the background reviewed, I prepare a written application for the patent. 


\section{Prosecuting Patent Applications}

Once a patent application is filed with the U.S. Patent and Trademark Office (USPTO), it is assigned to an examiner based upon the technology in the application. The examiner, who is generally well versed in the particular technical area involved, reviews the claims made in the patent application and compares the claims with what was publicly known about such technology, including knowledge demonstrated in existing patents or technical articles, which are referred to as "prior art." Any prior art is then referenced in an official document sent to the patent applicant with an explanation as to why the disclosed invention in the application does or does not meet the requirements for patentability.

The views of the examiner can be rebutted based on legal or technical grounds, which often requires me to draw on my technical materials education. For example, in a case involving the formation of hard constituents in an alloy, I recently met with an examiner to review the invention and the cited prior art. Our discussion included a review of scanning electron micrographs of the invention and the prior art reference, a review of a reference handbook (i.e., The Metals Handbook), and a discussion of solid solution processing and powder processing below the melt temperature. Ultimately, I was able to demonstrate to the examiner that the hard constituents in the alloy of the invention were not disclosed in the prior art even though the starting materials were similar due to the fact that the prior art utilized solid solution processing. In this case, solid solution processing precluded the formation of the hard constituents, which would be formed from metal carbides retained from the starting materials. Part of this discussion relied on mathematical modeling of the energetics of the reaction to demonstrate what was the energetically favored reaction path, an analysis based on chemical potentials of the constituent elements.

\section{Evaluating Products and Enforcing Patent Rights}

Once a patent is granted, the process moves into the enforcement phase. Generally, a patent grants the patent owner the right to prevent someone else from making, using, or selling the invention as described in the patent claims. Although the definition is relatively straightforward, it can be difficult to apply the definition and determine when a competitor's product or process is actually infringing upon the patent rights, and the assessment generally requires an evaluation of a product.

With respect to materials, particularly for compositions, the evaluation of a product provides me with another opportunity to delve into the science. When reviewing a composition patent claim, I study compositional analysis, micrographs, and materials properties to technically evaluate the product and compare that information to the features of the claims of the patent.

In evaluating potential infringing products, it is particularly important to apply an independent analysis. Therefore, I rely heavily on my technical skills when analyzing a product for potential infringement. Additionally, if I need further technical information, I research additional background information regarding the materials science at the foundation of the patent claim to sufficiently educate myself on the topic.

Enforcement may also involve evaluating other parties' technical positions. Actual lawsuits are often the culmination of multiple prior exchanges of information, including the exchange of legal and technical positions. Sometimes these positions are conveyed in a letter, which allows reflection and study; other times, the information is presented at a meeting without extensive time for study. In the latter instance, a deep and thorough technical understanding of materials science is useful to allow for immediate evaluation and timely inquiries. This may be even more essential if the technical information is presented in a confidential manner and cannot be shared (or can only be shared in a limited fashion) with the technical experts, such as the inventors.

\section{Education}

Finally, one aspect of my profession that is similar to, but not dependent on, my technical background is the continued education of both my clients and me.

Patent law, and the law in general, is continuously changing. Changes arise both from the law created during court cases and from changes in rules and procedures at the USPTO. The past year has seen changes that made an impact on almost every aspect of patent law from how patent applications are prepared and prosecuted to how granted patents are enforced and licensed.

This shifting landscape presents challenges and opportunities that will be familiar to those in a technical field. I constantly read legal resources to stay abreast of recent developments, much as researchers review journal articles to learn of the most recent developments. In addition, the changes produce an opportunity to inform (i.e., teach) clients and provide recommendations on new strategies or procedures to maximize protection and value of intellectual property assets.

In the end, being a patent attorney provides the opportunity to combine legal and scientific knowledge. For me, it has allowed continued application and education in the technical area of materials science within the legal landscape.

Jeffrey G. Killian works in the Washington D.C. office of Drinker Biddle $\mathcal{E}$ Reath, LLP. In addition to his undergraduate degree from the Massachusetts Institute of Technology and graduate work at the Johns Hopkins University, both in materials science, he was an officer of the nuclear-powered submarine in the U.S. Nary. Killian received his JD from Georgetown University Law Center in 2004. His legal practice focuses on obtaining, counseling, and enforcing intellectual property rights in the areas of materials science, including alloys, metal working, nanotechnology, and mining and construction. The views and opinions in this article are solely the author's.

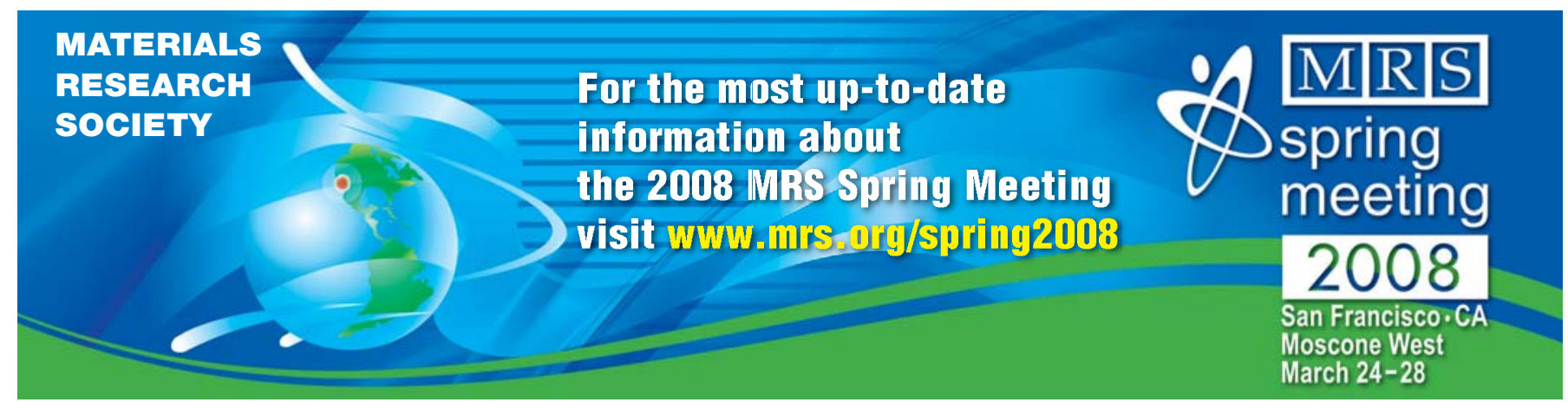

